\title{
Low-density lipoprotein cholesterol goal attainment rates in high-risk patients with cardiovascular diseases and diabetes mellitus in Korea: a retrospective cohort study
}

Ye Seul Yang ${ }^{1 \dagger}$, Bo Ram Yang ${ }^{2 \dagger}$, Mi-Sook Kim ${ }^{2,3}$, Yunji Hwang ${ }^{4}$ and Sung Hee Choi ${ }^{1,5^{*}}$ (i)

\begin{abstract}
Background: Real-world evidence of low-density lipoprotein cholesterol (LDL-C) goal attainment rates for Asian patients is deficient. The objective of this study was to assess the status of dyslipidemia management, especially in high-risk patients with cardiovascular disease (CVD) including stroke and acute coronary syndrome (ACS).

Methods: This was a retrospective cohort study of 514,866 subjects from the National Health Insurance ServiceNational Health Screening Cohort database in Korea. Participants were followed up from 2002 to 2015. Subjects with a high-risk of CVD prior to LDL-C measurement and subjects who were newly-diagnosed for high-risk of CVD following LDL-C measurement were defined as known high-risk patients $(n=224,837)$ and newly defined high-risk patients $(n=127,559)$, respectively. Data were analyzed by disease status: stroke, ACS, coronary heart disease (CHD), peripheral artery disease (PAD), diabetes mellitus (DM) and atherosclerotic artery disease (AAD).

Results: Overall, less than $50 \%$ of patients in each disease category achieved LDL-C goals (LDL-C $<70 \mathrm{mg} / \mathrm{dL}$ in patients with stroke, ACS, CHD and PAD; and LDL-C $<100 \mathrm{mg} / \mathrm{dL}$ in patients with $\mathrm{DM}$ and $A A D)$. Statin use was observed in relatively low proportions of subjects (21.5\% [known high-risk], 34.4\% [newly defined high-risk]). LDL-C goal attainment from 2009 to 2015 steadily increased but the goal-achiever proportion of newly defined high-risk patients with ACS remained reasonably constant (38.7\% in 2009; $38.1 \%$ in 2015).

Conclusions: LDL-C goal attainment rates in high-risk patients with CVD and DM in Korea demonstrate unmet medical needs. Proactive management is necessary to bridge the gap between the recommendations of clinical guidelines and actual clinical practice.
\end{abstract}

Keywords: Dyslipidaemia, Low density lipoprotein cholesterol, Stroke, Acute coronary syndrome, Cardiovascular disease, Diabetes mellitus, Statin

\footnotetext{
* Correspondence: shchoimd@gmail.com

${ }^{\dagger}$ Ye Seul Yang and Bo Ram Yang contributed equally to this work.

'Department of Internal Medicine, Seoul National University College of

Medicine, 101 Daehak-ro, Jongno-gu, Seoul, Republic of Korea

${ }^{5}$ Department of Internal Medicine, Division of Endocrinology \& Metabolism,

Seoul National University Bundang Hospital, 82, Gumi-ro 173Beon-gil,

Bundang-gu, Seongnam-si, Gyeonggi-do, Republic of Korea

Full list of author information is available at the end of the article
}

(c) The Author(s). 2020 Open Access This article is distributed under the terms of the Creative Commons Attribution 4.0 International License (http://creativecommons.org/licenses/by/4.0/), which permits unrestricted use, distribution, and reproduction in any medium, provided you give appropriate credit to the original author(s) and the source, provide a link to the Creative Commons license, and indicate if changes were made. The Creative Commons Public Domain Dedication waiver (http://creativecommons.org/publicdomain/zero/1.0/) applies to the data made available in this article, unless otherwise stated. 


\section{Introduction}

Cardiovascular disease (CVD) is the leading cause of death globally, with 17.9 million estimated deaths from CVD in 2016, representing 31\% of all global deaths. Myocardial infarction and stroke account for $85 \%$ of CVD deaths [1]. Dyslipidemia is a major risk factor for coronary heart disease (CHD) and stroke [2-5], and includes elevated total cholesterol, triglycerides, or lowdensity lipoprotein cholesterol (LDL-C) levels, or low high-density lipoprotein cholesterol (HDL-C) levels. The global disease burden of CVD increased by $12.5 \%$ [6], and this trend is attributed by Asians with fast growing of aged population [7]. However, evidence is limited for dyslipidemia management for high-risk CVD patients among Asians. Recent data from the Korean National Health and Nutrition Examination Survey (KNHANES) reported that, in 2016, $19.9 \%$ of adults aged $\geq 30$ years had hypercholesteremia and 40.5\% had dyslipidemia [8]. The prevalence of dyslipidemia in Korea has increased in an age-dependent manner and is more evident in women aged $\geq 50$ years [8-11]. The level of disease awareness was as low as $32.1 \%$ in men and $32.6 \%$ in women (aged 30-49 years) [11]. In one recent study in Korea, the prevalence of dyslipidemia was higher than that of hypertension and diabetes mellitus (DM), but dyslipidemia awareness and treatment rates were still lower [12].

LDL-C remains the primary target of cholesterollowering therapy for the primary and secondary prevention of atherosclerotic cardiovascular disease (ASCVD) events including $\mathrm{CHD}$, stroke, and peripheral artery disease (PAD). The cardiovascular risk level of individuals determines LDL-C treatment goals [2-4, 13-15]. Some differences in cholesterol-lowering guidelines have been described and these may, at least in part, be attributable to whether the guidelines are solely evidence-based or based on a combination of evidence and expert opinion $[16,17]$. On the other hand, management of dyslipidemia was revolutionized since statins were discovered. Statins are known to substantially reduce LDL-C levels and CVD mortality [18, 19]. Previous studies have shown that further reductions in LDL-C levels by more intensive statin therapy according to the risk of CVD have further benefits [20,21].

American College of Cardiology/American Heart Association (ACC/AHA) guidelines [3] emphasized > 50\% LDL-C reductions from baseline in high-risk patients. European Society of Cardiology and European Atherosclerosis Society (ESC/EAS) guidelines in 2016 focused on $<70 \mathrm{mg} / \mathrm{dL}$ LDL-C reductions in high-risk patients [15]. Recently revised 2018 ACC/AHA guidelines emphasize using an LDL-C threshold of $70 \mathrm{mg} / \mathrm{dL}$ for considering the addition of non-statins to statin therapy in very high-risk patients, including a history of multiple major ASCVD events or one major ASCVD event and multiple high-risk conditions [22]. This means that, in addition to percent LDL-C reductions from baseline, target LDL-C levels are also critical values as LDL-C treatment goals for dyslipidemia management. The latest Korean national guidelines were formulated from the Committee of Clinical Practice of the Korean Society of Lipid and Atherosclerosis for the Management of Dyslipidemia in 2018 [23]. It was generally based on the third report of the National Cholesterol Education Program-Adult Treatment Panel (NECP-ATP) [2] for the risk stratification and LDL-C treatment goal. However, > 50\% LDL-C reduction was recommended according to ACC/AHA guidelines in case of ACS patients in addition to the LDL-C target $<70 \mathrm{mg} / \mathrm{dL}$ and intensity of statin also was recommend in accordance with the ACC/AHA guidelines [3]. The target of the recent American Association of Clinical Endocrinologists guideline [4] for lowering LDL-C to less than 55 for extreme high risk was not included in the recommendations yet as consensus from domestic experts will be required.

Evidence of LDL-C goal attainment rates for Korean patients compared with other recently updated guidelines is currently lacking, particularly in high-risk patients. Therefore, it is needed to evaluate the status of dyslipidemia management in Korea in general, as well as specifically addressing the status of high-risk patients with stroke, acute coronary syndrome (ACS), CHD, PAD, DM and atherosclerotic artery disease (AAD). This study used absolute values for LDL-C level $<70 \mathrm{mg} / \mathrm{dL}$ in patients with very-high risk disease (stroke, ACS, $\mathrm{CHD}$ and PAD) and $<100 \mathrm{mg} / \mathrm{dL}$ LDL-C in high-risk patients (DM and $\mathrm{AAD}$ ); and $>50 \%$ reduction using repeated measured LDL-C levels, as LDL-C treatment goals. Also, this study aimed to describe the time trends of LDL-C goal attainment rate in recent years using extensive national data. To identify the most appropriate populations to target with preventative therapies, subgroup analyses were conducted.

\section{Methods \\ Study design}

This retrospective cohort study used data from the Korean National Health Insurance Service-National Health Screening Cohort (NHIS-HEALS), details of which have been described elsewhere [24]. The NHIS has provided a general national health screening program since 1995, and a health screening program for transitional ages, aimed at individuals aged 40 and 66 years, since 2007. The general health screening program is applied at least once every 2 years for the entire population of Korean adults aged $\geq 40$ years; the participation rate was $74.8 \%$ in 
2014. NHIS-HEALS incorporates information from these health screening programs [25].

The NHIS-HEALS database comprised 514,866 subjects (aged $40-79$ years, $54.2 \%$ males) at baseline (20022003) who were randomly selected by simple random sampling using SAS version 9.4 (SAS Institute Inc., Cary, NC, USA) and represented $10 \%$ of all national health screening participants $(N=5,148,695)$ in 2002 and 2003. Participants were followed up from 2002 to 2015 and data constructed in 2015. Variables included social and economic qualifications, medical check-up results, healthcare usage and survival status linked to national death certificates [24]. The healthcare usage database included information on records of inpatient and outpatient usage (diagnosis, procedures, and prescriptions). Diagnoses were coded according to the International Classification of Disease, Tenth Revision (ICD-10) [26].

\section{Risk stratification}

Korean national guidelines [23] based on the risk stratification of NCEP-ATP III, categorized risk groups to very high-risk, high-risk, moderate-risk and low-risk and recommended LDL-C treatment goals dependent on risk assessment: very high-risk $<70 \mathrm{mg} / \mathrm{dL}$, high-risk $<100$ $\mathrm{mg} / \mathrm{dL}$, moderate-risk $<130 \mathrm{mg} / \mathrm{dL}$, and low-risk $<160$ $\mathrm{mg} / \mathrm{dL}$. Very high-risk consisted of ACS, stroke and TIA, and PAD; high-risk consisted of carotid artery disease, abdominal aortic aneurysm, and DM. According to guidelines, PAD and other AAD (including carotid artery disease and abdominal aortic aneurysm) were separated to adjust different LDL-C target goal. ICD-10 codes and related procedures for risk stratification were listed in Table 1.

Table 1 Definition of high-risk disease by ICD-10 codes and procedure code

\begin{tabular}{|c|c|}
\hline Disease & Diagnosis or procedure code \\
\hline Stroke & Diagnosis: $163^{\mathrm{a}}, 164^{\mathrm{a}}, 169.3^{\mathrm{b}}, \mathrm{G} 45, \mathrm{G} 46$ \\
\hline \multirow[t]{5}{*}{ ACS } & Diagnosis: $121^{\mathrm{a}}, 122^{\mathrm{a}}, 123$ \\
\hline & Procedure: \\
\hline & $\begin{array}{l}\text { Coronary artery bypass graft: OA640-2, OA647-9, O1640-2, } \\
\text { O1647-9 }\end{array}$ \\
\hline & Percutaneous coronary intervention: M6561-7, M6571-2 \\
\hline & Percutaneous transluminal coronary angioplasty: M6551-4 \\
\hline $\mathrm{CHD}$ & Diagnosis: 120.0, 120.9, 124.0, 125.1, 125.2 \\
\hline PAD & Diagnosis: 170.2, 173.1, 173.8, 173.9 \\
\hline DM & Diagnosis: E10, E11, E12, E13, E14 \\
\hline AAD & Diagnosis: 165.2, 171.3, 171.4, 171.5, 171.6 \\
\hline
\end{tabular}

$A A D$ atherosclerotic artery disease, $A C S$ acute coronary syndrome, $C H D$ coronary heart disease, $D M$ diabetes mellitus, $I C D$-10 International Classification of Diseases (10th revision), PAD peripheral artery disease ${ }^{\mathrm{a}}$ Included only in the case of hospitalization; ${ }^{\mathrm{b}}$ Included for Known high risk

\section{Eligibility criteria}

From the NHIS-HEALS database, patients with LDL-C measurements during 2007-2013 were included. Although data on participants' total cholesterol levels are available from 2002, data for triglyceride, HDL-C and LDL-C levels are available for the health screening program for transitional ages from 2007, and for general national health screening programs from 2009. Patients with LDL-C measurement $<10 \mathrm{mg} / \mathrm{dL}$ during 20072013 were excluded. Subjects with a high-risk of CVD including stroke, ACS, CHD, PAD, DM and AAD were identified using ICD-10 codes and related procedures (Table 1) and classified into two groups: 1) known highrisk patients, 2) newly defined high-risk patients (Fig. 1).

Subjects previously identified as having a high-risk for CVD, prior to measurement of LDL-C levels, were categorized as "known high-risk patients." The index date is the first LDL-C testing date during the study period. Definition of high-risk status was required to be made in the previous year including the index date. Subjects categorized as "newly defined high-risk" were identified according to the following criteria: 1) patients with more than two LDL-C measurements, and 2) patients who were newly diagnosed or underwent procedures for high-risk CVD between two LDL-C measurements. As LDL-C levels were available from 2007, patients with new cases of each disease could be defined as having at least 5 years of disease-free periods. For subjects with newly defined high-risk disease, the earliest date of visit regarding high-risk disease was defined as the index date. Here is an example of the group definition. If a subject had five LDL-C measurements during the follow up period and there was a first diagnosis of DM prior to the first LDL-C measurement, he or she was defined as a known high-risk patient for DM; on the other hand, there was a first ACS diagnosis between the third and fourth LDL-C measurements, he or she was defined as a newly diagnosed high-risk patient for ACS.

\section{Outcome variables: LDL-C goal attainment}

Target LDL-C levels were defined by the 2018 Korean guidelines [23]. For patients with stroke, ACS, CHD or PAD, defined as the very high-risk group, the target level was $<70 \mathrm{mg} / \mathrm{dL}$. For patients with $\mathrm{DM}$ or AAD, defined as high-risk group, the target level was $<100 \mathrm{mg} / \mathrm{dL}$. When patients with DM or AAD had other concurrent high-risk diseases-stroke, ACS, $\mathrm{CHD}$ or PAD-these patients were stratified into the subgroups "DM with high-risk of CVD" and "AAD with high-risk of CVD" for outcome analysis, because their target level was $<70 \mathrm{mg} / \mathrm{dL}$ as very high-risk group. To determine LDL-C target achievement, LDL$\mathrm{C}$ levels at the index date and LDL-C levels after the 


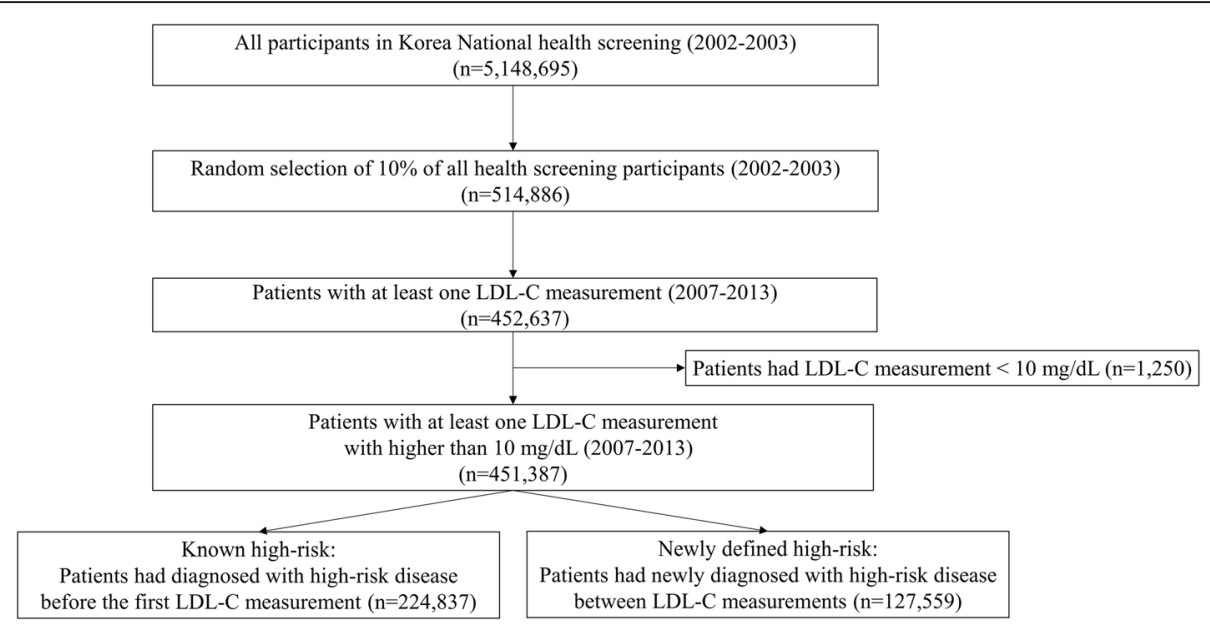

Fig. 1 Flow chart of the selection of high-risk category subjects

index date were used for known high-risk patients and newly defined high-risk patients, respectively.

LDL-C goal attainment by reduction rates were defined by 2013 ACC/AHA guidelines: $>50 \%$ reduction in baseline LDL-C for high-intensity statin and 30 to $<50 \%$ for moderate-intensity statin; guidelines recommend highintensity statin therapy in patients with ASCVD or those with DM aged $>45$ years [3]. In the present study, the two LDL-C levels just before and after the index date of newly defined high-risk patients were used to calculate changes in LDL-C levels. On average, the interval for the two LDL$\mathrm{C}$ tests was approximately 1 year, due to government policy for providing the health screening program.

\section{Assessment of statin use}

Statins included atorvastatin, fluvastatin, lovastatin, pitavastatin, pravastatin, rosuvastatin and simvastatin. Statin therapy intensity was classified as high-intensity (atorvastatin $40-80 \mathrm{mg}$, rosuvastatin $20 \mathrm{mg}$ ), moderate-intensity (atorvastatin $10-20 \mathrm{mg}$, fluvastatin $40-80 \mathrm{mg}$, lovastatin $40 \mathrm{mg}$, pitavastatin $2-4 \mathrm{mg}$, pravastatin $40 \mathrm{mg}$, rosuvastatin 5-10 mg, simvastatin $20-40 \mathrm{mg}$ ), and low-intensity (fluvastatin $20-40 \mathrm{mg}$, lovastatin $20 \mathrm{mg}$, pitavastatin 1 $\mathrm{mg}$, pravastatin 5-20 mg, simvastatin 5-10 mg), according to generic name and dose.

Statin exposure was assessed on or within 30 days before the index date using the prescription date and duration in known high-risk patients. For newly defined high-risk patients, whether exposure to statin took place from 30 days before to 90 days after the index date, using prescription dates and duration was assessed. Subjects were classified by their statin use history, as existing users if receiving statins at the time of the index date or within 6 months before the index date, or new users if there was no record of statin use for 6 months prior to the index date.

\section{Data analysis}

General characteristics including age, sex, body mass index (BMI), waist circumference, smoking, presence of diabetes, presence of hypertension, systolic and diastolic blood pressure measurements, fasting blood glucose levels, total cholesterol, triglyceride, HDL-C and LDL-C, are presented as mean and standard deviation (SD) for continuous variables and as frequency and proportion for categorical variables.

The proportion of patients attaining target LDL-C levels was calculated by dividing the number of patients with LDL-C level less than target level by the total number of patients. The proportion of patients with $>50 \%$ reduction of LDL-C levels was calculated by dividing the number of patients with $>50 \%$ reduction of LDL-C from the previous LDL-C level by the total number of patients. All LDL-C measurements from the index date were included to identify annual trend. Data were analyzed by disease status: stroke, ACS, CHD, PAD, DM and AAD. Data were analyzed using SAS Enterprise Guide 7.1 (SAS Institute, Cary, North Carolina, USA).

\section{Results}

\section{Patients' characteristics}

The NHIS-HEALS database $(n=514,866)$ included highrisk patients either before LDL-C measurement (known high-risk; $n=224,837$ ) or following LDL-C measurement (newly defined high-risk; $n=127,559$ ) (Fig. 1). Baseline characteristics of subjects stratified by cardiovascular risk category (known or newly defined high-risk), and by disease, are shown in Tables 2 and 3. DM was the most common disease in the known high-risk group $(n=153$, $050)$, followed by PAD $(n=89,807)$, and CHD $(n=65$, 868). In patients with newly defined high-risk for CVD, PAD $(n=55,767)$ was the most common disease followed by DM $(n=52,416)$, and CHD $(n=29,434)$ 
(Tables 2 and 3). Mean age was similar across patient groups (62-66 years; known high-risk and newly defined high-risk). For ACS (67.89\%), CHD (52.82\%), DM (52.31\%) and AAD (62.87\%), more than half of all patients were men; for stroke (49.53\%) and PAD (47.66\%), less than half of the patients were men.

\section{Statin use}

Relatively low proportions of subjects were under lipidlowering therapy with statin (21.5\% [known high-risk], $34.4 \%$ [newly defined high-risk]). Among statin users, most patients in both the known and newly defined high-risk groups received moderate-intensity statin therapy (89.392.5\%). High-intensity statin therapy was least commonly used in known high-risk patients, but more frequent in newly defined high-risk patients: 2.8 and $12.5 \%$ (stroke), 6.1 and 32.0\% (ACS), 2.7 and 8.3\% (CHD), 1.8 and 3.0\% (PAD), 2.0 and $4.4 \%(\mathrm{DM})$, and 3.3 and $10.4 \%$ (AAD), respectively.

Overall, 22.6 and $40.1 \%$ of known high-risk and newly defined high-risk stroke patients, respectively, received statin therapy (Fig. 2). For stroke patients defined as the known high-risk group $(n=39,317), 1.5,20.5$ and $0.6 \%$ received low-, moderate- or high-intensity statin therapy, respectively. For stroke patients defined as the newly defined highrisk $(n=17,410)$, corresponding values were 1.6, 33.5 and $5.0 \%$. Overall, $49.4 \%$ of ACS patients with known high-risk received statin therapy versus $78.0 \%$ of patients with newly defined high-risk. In ACS patients with known high-risk ( $n=5309$ ), 2.3, 44.1 and 3.0\% received low-, moderate- or high-intensity statin therapy, respectively; corresponding values were $1.1,52.0$ and $24.9 \%$, in ACS patients with newly defined high-risk $(n=2479)$. This difference was largely due to a higher proportion of newly defined high-risk patients receiving high-intensity statin therapy compared with known high-risk patients (24.9\% vs. 3.0\%) (Fig. 2).

Statins were also used more frequently in newly defined high-risk patients compared with known high-risk patients in CHD (40.8\% vs. $27.3 \%)$, PAD $(27.1 \%$ vs. $17.5 \%)$, DM (32.1\% vs. $19.8 \%)$ and $\mathrm{AAD}(61.3 \%$ vs. $44.2 \%$ ) (Fig. 2). In newly defined high-risk stroke patients $(n=17,410), 23.1 \%$ were existing statin users and $17.0 \%$ were new statin users. In newly defined high-risk ACS patients $(n=2479), 31.7 \%$ were existing users, and $46.2 \%$ were new users (Fig. 3).

\section{LDL-C goal attainment rates}

LDL-C goal attainment rates in all high-risk patients (known plus newly defined), defined according to target LDL-C level and stratified by disease, are shown in Fig. 4a. LDL-C goal attainment rates in stroke patients $(n=56$, $727)$ for $<70 \mathrm{mg} / \mathrm{dL}$ were $11.7 \%$; and in ACS patients $(n=$ $7788)$ were $26.3 \%$. In CHD patients $(n=95,302)$, LDL-C attainment rates for $<70 \mathrm{mg} / \mathrm{dL}$ were $12.7 \%$; and, in PAD patients $(n=145,574)$, were $9.2 \%$ (Fig. $4 \mathrm{a})$.

Table 2 Baseline characteristics in subjects stratified by cardiovascular risk category and disease: known high-risk patients

\begin{tabular}{|c|c|c|c|c|c|c|}
\hline & $\begin{array}{l}\text { Stroke } \\
(\mathrm{n}=39,317)\end{array}$ & $\begin{array}{l}\text { ACS } \\
(n=5309)\end{array}$ & $\begin{array}{l}\text { CHD } \\
(n=65,868)\end{array}$ & $\begin{array}{l}\text { PAD } \\
(n=89,807)\end{array}$ & $\begin{array}{l}\mathrm{DM} \\
(\mathrm{n}=153,050)\end{array}$ & $\begin{array}{l}\text { AAD } \\
(n=2200)\end{array}$ \\
\hline Mean age, years $( \pm S D)$ & $65.39 \pm 9.43$ & $65.09 \pm 9.39$ & $63.41 \pm 9.21$ & $63.79 \pm 9.39$ & $62.63 \pm 9.11$ & $66.45 \pm 9.02$ \\
\hline Male, $n(\%)$ & $18,575(47.24)$ & $3442(64.83)$ & $34,431(52.27)$ & $38,262(42.6)$ & $80,104(52.34)$ & $1380(62.73)$ \\
\hline Mean BMl, kg/m² $( \pm S D)$ & $24.28 \pm 3.16$ & $24.35 \pm 3.16$ & $24.51 \pm 3.08$ & $24.33 \pm 3.15$ & $24.39 \pm 3.11$ & $24.05 \pm 3.06$ \\
\hline Mean waist circumference, $\mathrm{cm}( \pm \mathrm{SD})$ & $83.5 \pm 8.52$ & $84.69 \pm 8.37$ & $83.94 \pm 8.42$ & $83.06 \pm 8.5$ & $83.69 \pm 8.43$ & $84.19 \pm 8.47$ \\
\hline \multicolumn{7}{|l|}{ Smoking, $n(\%)$} \\
\hline non-smoker & $27,731(71.56)$ & $3029(58.07)$ & $43,183(66.65)$ & $64,638(72.92)$ & $99,636(66.21)$ & $1291(59.69)$ \\
\hline former smoker & $6549(16.90)$ & $1370(26.27)$ & $12,980(20.03)$ & $12,987(14.65)$ & $27,958(18.58)$ & $533(24.64)$ \\
\hline current smoker & $4474(11.54)$ & $817(15.66)$ & $8625(13.31)$ & $11,012(12.42)$ & $22,887(15.21)$ & $339(15.67)$ \\
\hline $\mathrm{DM}, n(\%)$ & $23,175(58.94)$ & $3806(71.69)$ & $38,946(59.13)$ & $46,651(51.95)$ & $153,050(100.0)$ & $1477(67.14)$ \\
\hline Hypertension, $n$ (\%) & $30,727(78.15)$ & $4759(89.64)$ & $52,413(79.57)$ & $61,991(69.03)$ & $102,151(66.74)$ & $1918(87.18)$ \\
\hline Mean systolic BP, mmHg $( \pm \mathrm{SD})$ & $128.08 \pm 15.79$ & $126.98 \pm 16.2$ & $127.34 \pm 15.54$ & $127.71 \pm 15.71$ & $127.37 \pm 15.5$ & $128.45 \pm 16.43$ \\
\hline Mean diastolic $\mathrm{BP}, \mathrm{mmHg}( \pm \mathrm{SD})$ & $78.06 \pm 10.06$ & $77.11 \pm 10.24$ & $77.8 \pm 9.99$ & $78.1 \pm 9.99$ & $77.9 \pm 9.91$ & $77.51 \pm 10.23$ \\
\hline Mean total cholesterol, mg/dL $( \pm S D)$ & $194.21 \pm 40.18$ & $177.03 \pm 40.72$ & $191.38 \pm 39.68$ & $198.2 \pm 39.88$ & $195.06 \pm 39.69$ & $183.39 \pm 41.46$ \\
\hline Mean triglycerides, mg/dL $( \pm \mathrm{SD})$ & $141.79 \pm 83.48$ & $139.2 \pm 79.8$ & $140.41 \pm 83.85$ & $141.98 \pm 84.27$ & $144.76 \pm 88.7$ & $134.63 \pm 75.27$ \\
\hline Mean HDL-C level, mg/dL ( \pm SD) & $53.6 \pm 31.11$ & $52.22 \pm 36.79$ & $53.45 \pm 28.84$ & $54.2 \pm 27.02$ & $53.47 \pm 27.19$ & $51.48 \pm 21.36$ \\
\hline Mean LDL-C level, mg/dL ( \pm SD) & $114.02 \pm 38.97$ & $99.71 \pm 39.85$ & $111.47 \pm 39.52$ & $116.79 \pm 38.37$ & $113.99 \pm 38.62$ & $106.1 \pm 41.52$ \\
\hline Mean fasting plasma glucose, $\mathrm{mg} / \mathrm{dL}( \pm \mathrm{SD})$ & $104.49 \pm 29.4$ & $108.7 \pm 35.96$ & $105.12 \pm 29.52$ & $104.62 \pm 29.76$ & $111.58 \pm 35.65$ & $106.7 \pm 31.86$ \\
\hline
\end{tabular}

* Variables from the health screening program were included missing data. Missing rates (\%) are 0.08 for BMI, 0.10 for waist circumference, 1.55 for Smoking, 0.04 for systolic BP, 0.04 for diastolic BP, 0.001 for total cholesterol, 0.08 for triglycerides, 0.004 for HDL-C level, 0.000 for LDL-C, and 0.002 for fasting plasma glucose $A A D$ atherosclerotic artery disease, $A C S$ acute coronary syndrome, $C H D$ coronary heart disease, $D M$ diabetes mellitus, $P A D$ peripheral artery disease 
Table 3 Baseline characteristics in subjects stratified by cardiovascular risk category and disease: newly defined high-risk patients

\begin{tabular}{|c|c|c|c|c|c|c|}
\hline & $\begin{array}{l}\text { Stroke } \\
(n=17,410)\end{array}$ & $\begin{array}{l}\text { ACS } \\
(n=2479)\end{array}$ & $\begin{array}{l}\text { CHD } \\
(n=29,434)\end{array}$ & $\begin{array}{l}\text { PAD } \\
(n=55,767)\end{array}$ & $\begin{array}{l}\text { DM } \\
(n=52,416)\end{array}$ & $\begin{array}{l}\text { AAD } \\
(n=4624)\end{array}$ \\
\hline Mean age, years $( \pm S D)$ & $65.22 \pm 8.76$ & $65.71 \pm 8.8$ & $63.61 \pm 8.51$ & $63.21 \pm 8.41$ & $61.92 \pm 8.3$ & $65.74 \pm 8.18$ \\
\hline Male, $n(\%)$ & $8623(49.53)$ & $1683(67.89)$ & $15,547(52.82)$ & $26,576(47.66)$ & $27,417(52.31)$ & $2907(62.87)$ \\
\hline Mean BMl, kg/m² $( \pm S D)$ & $24.2 \pm 2.96$ & $24.47 \pm 3.01$ & $24.42 \pm 3$ & $24.25 \pm 2.95$ & $24.41 \pm 3$ & $24.21 \pm 2.81$ \\
\hline Mean waist circumference, $\mathrm{cm}( \pm \mathrm{SD})$ & $82.99 \pm 8.31$ & $84.94 \pm 8$ & $83.44 \pm 8.28$ & $82.73 \pm 8.29$ & $83.09 \pm 8.33$ & $83.72 \pm 8.07$ \\
\hline \multicolumn{7}{|l|}{ Smoking, $n(\%)$} \\
\hline non-smoker & $11,835(68.66)$ & $1294(52.84)$ & $19,085(65.55)$ & $38,415(69.63)$ & $33,675(64.96)$ & $2636(57.57)$ \\
\hline former smoker & 3015 (17.49) & $536(21.89)$ & $5679(19.5)$ & $9508(17.23)$ & $10,006(19.3)$ & $1133(24.74)$ \\
\hline current smoker & $2387(13.85)$ & $619(25.28)$ & $4353(14.95)$ & $7249(13.14)$ & $8162(15.74)$ & $810(17.69)$ \\
\hline $\mathrm{DM}, n(\%)$ & $8393(48.21)$ & $1274(51.39)$ & $13,860(47.09)$ & $24,589(44.09)$ & $0(0.00)$ & $2650(57.31)$ \\
\hline Hypertension, $n$ (\%) & $10,910(62.67)$ & $1708(68.90)$ & $18,210(61.87)$ & $32,098(57.59)$ & $26,890(51.30)$ & $3300(71.37)$ \\
\hline Mean systolic BP, mmHg $( \pm \mathrm{SD})$ & $127.83 \pm 15.67$ & $129.22 \pm 15.25$ & $127.53 \pm 15.42$ & $126.89 \pm 15.48$ & $127.13 \pm 15.46$ & $128.4 \pm 15.15$ \\
\hline Mean diastolic BP, mmHg $( \pm \mathrm{SD})$ & $78.18 \pm 10.04$ & $78.41 \pm 9.85$ & $78.26 \pm 10.03$ & $77.86 \pm 9.96$ & $78.48 \pm 10.06$ & $77.78 \pm 9.84$ \\
\hline Mean total cholesterol, mg/dL ( \pm SD) & $199.09 \pm 39$ & $202.64 \pm 43.09$ & $199.54 \pm 38.93$ & $199.22 \pm 38.59$ & $203.88 \pm 39.46$ & $195.52 \pm 40.2$ \\
\hline Mean triglycerides, mg/dL $( \pm \mathrm{SD})$ & $140.53 \pm 82.41$ & $153.91 \pm 88.65$ & $141.5 \pm 84.77$ & $138.95 \pm 83.78$ & $146.67 \pm 91.49$ & $139.7 \pm 80.57$ \\
\hline Mean HDL-C level, mg/dL ( \pm SD) & $53.49 \pm 23.68$ & $50.51 \pm 18.84$ & $53.69 \pm 24.23$ & $54.42 \pm 24.76$ & $54.15 \pm 22.38$ & $52.06 \pm 16.44$ \\
\hline Mean LDL-C level, mg/dL ( \pm SD) & $118.37 \pm 37.42$ & $121.51 \pm 39.64$ & $118.52 \pm 37.17$ & $117.99 \pm 37$ & $121.2 \pm 37.28$ & $115.85 \pm 37.4$ \\
\hline Mean fasting plasma glucose, mg/dL ( \pm SD) & $103.58 \pm 28.42$ & $107.9 \pm 33.18$ & $103.76 \pm 27.51$ & $103.15 \pm 27.36$ & $106.94 \pm 30.32$ & $106.46 \pm 29.8$ \\
\hline
\end{tabular}

* Variables from the health screening program were included missing data. Missing rates (\%) for variables are 0.01 for BMI, 0.03 for waist circumference, 0.72 for Smoking, 0.02 for systolic BP, 0.02 for diastolic BP, 0.000 for total cholesterol, 0.09 for triglycerides, 0.002 for HDL-C level, 0.000 for LDL-C, and 0.001 for fasting plasma glucose

$A A D$ atherosclerotic artery disease, $A C S$ acute coronary syndrome, $C H D$ coronary heart disease, $D M$ diabetes mellitus, $P A D$ peripheral artery disease

Attainment rates for DM patients with a high-risk for CVD $(n=105,800)$ were higher for achieving $<70 \mathrm{mg} / \mathrm{dL}$ goals than for DM patients without high risk $(n=99$, 666) $(12.2 \%$ vs. $8.3 \%$, respectively). Attainment rates for $\geq 70$ to $<100 \mathrm{mg} / \mathrm{dL}$ ( $27.1 \%$ vs. $24.3 \%$ ) were comparable. Similarly, a higher proportion of patients with AAD with high-risk $(n=5415)$ achieved $<70 \mathrm{mg} / \mathrm{dL}$ goals than patients without high risk $(n=1409)(20.9 \%$ vs. $11.8 \%)$. Respective attainment rates for $\geq 70$ to $<100 \mathrm{mg} / \mathrm{dL}$ were $32.4 \%$ versus $28.7 \%$ (Fig. $4 \mathrm{a}$ ).

In newly defined high-risk patients, LDL-C goal attainment was defined as an LDL-C reduction $>50 \%$, according to ACC/AHA guidelines [3] (Fig. 4b). These goals were achieved in $34.5 \%$ of 6981 stroke patients, $57.8 \%$ of 1933 ACS patients, $35.5 \%$ of CHD patients $(n=12,021)$, $25.4 \%$ of PAD patients $(n=15,136), 31.4 \%$ of DM patients $(n=16,801)$, and by $35.1 \%$ of AAD patients $(n=$ 2836) (Fig. 4b).

Time trends of LDL-C goal attainment in known and newly defined high-risk patients in each disease group are shown in Fig. 5. In stroke patients, there were similar upward trends from 2009 to 2015 in both known (from 9.7 to $15.1 \%$ ) and newly defined (from 8.9 to $16.3 \%$ ) high-risk patients. In contrast, in ACS patients, the proportion of known high-risk patients achieving LDL-C goals increased steadily from 2009 to 2015 (from 19.7 to $27.6 \%)$, whereas the proportion of newly defined high- risk patients remained reasonably constant $(38.7 \%$ in 2009 and $38.1 \%$ in 2015).

In CHD and PAD patients, the time-trend curves for known and newly defined high-risk patients were virtually superimposable. In CHD patients, LDL-C goal attainment steadily increased from 2009 to 2015: from 11.4 to $16.6 \%$ in known, and 12.9 to $16.2 \%$ in newly defined high-risk patients. In PAD patients, goal attainment rates from 2009 to 2015 were 8.5 to $13.1 \%$ in known, and 9.3 to $11.7 \%$ in newly defined high-risk patients (Fig. 5).

Time trends in DM patients with or without high-risk showed that DM patients without high-risk consistently had higher LDL-C goal attainment rates than DM patients with high-risk, irrespective of the known or recent diagnosis of high-risk. Attainment rates in 2015 for DM patients without high-risk were 41.0 and $35.9 \%$, respectively, for known and newly defined high-risk groups, compared with rates of 18.1 and $14.3 \%$ for newly defined high-risk groups in DM patients with high-risk (Fig. 5).

Attainment rates of atherosclerosis patients with highrisk were generally similar in newly defined high-risk patients (16.1\% in $2011,25.4 \%$ in 2015$)$ compared with known high-risk patients (14.6\% in 2011, 20.8\% in 2015), although the attainment rate tended to be higher in newly defined high-risk than in known high-risk in 2009. However, in atherosclerosis without high-risk, attainment rates 


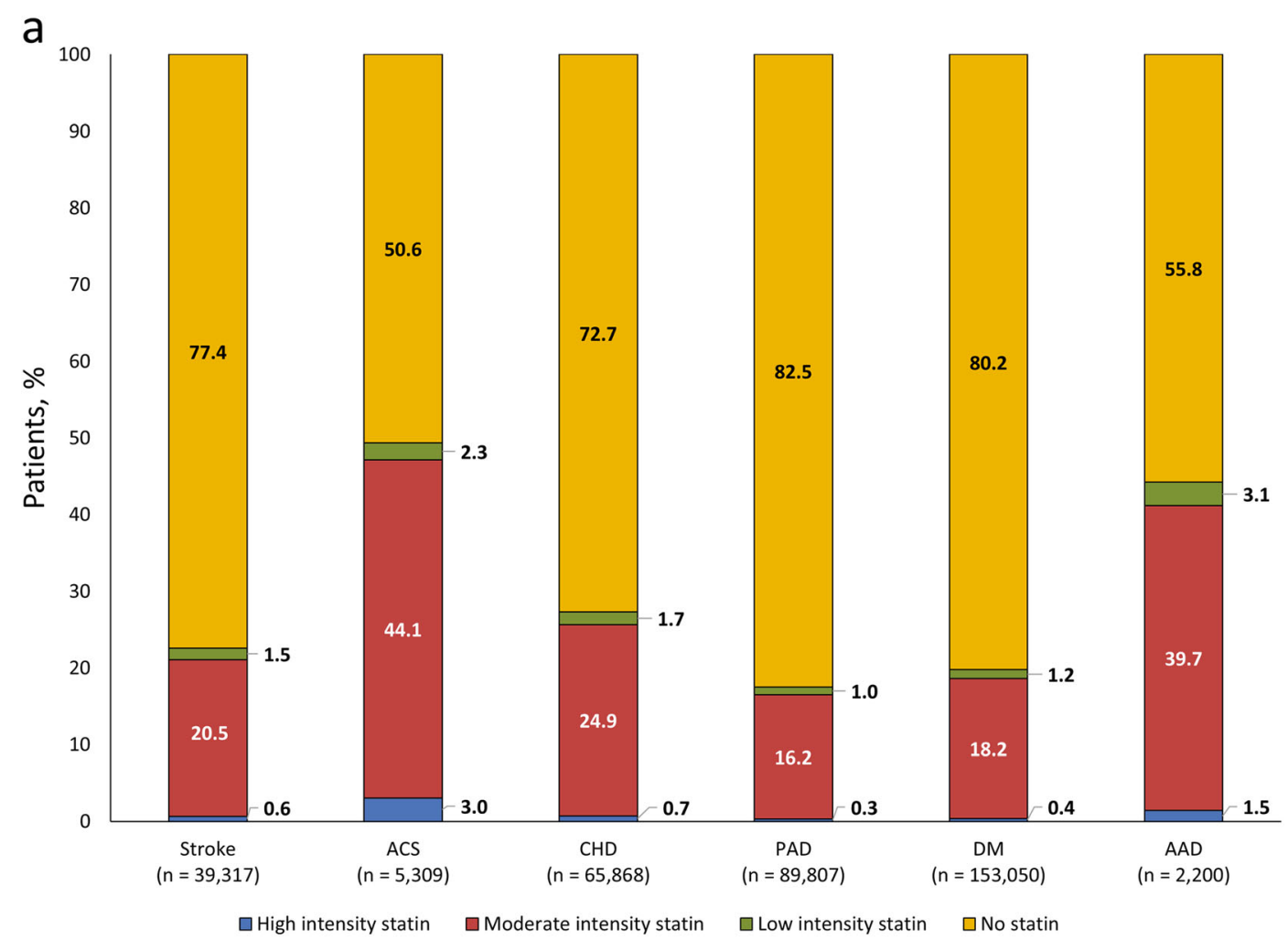

b

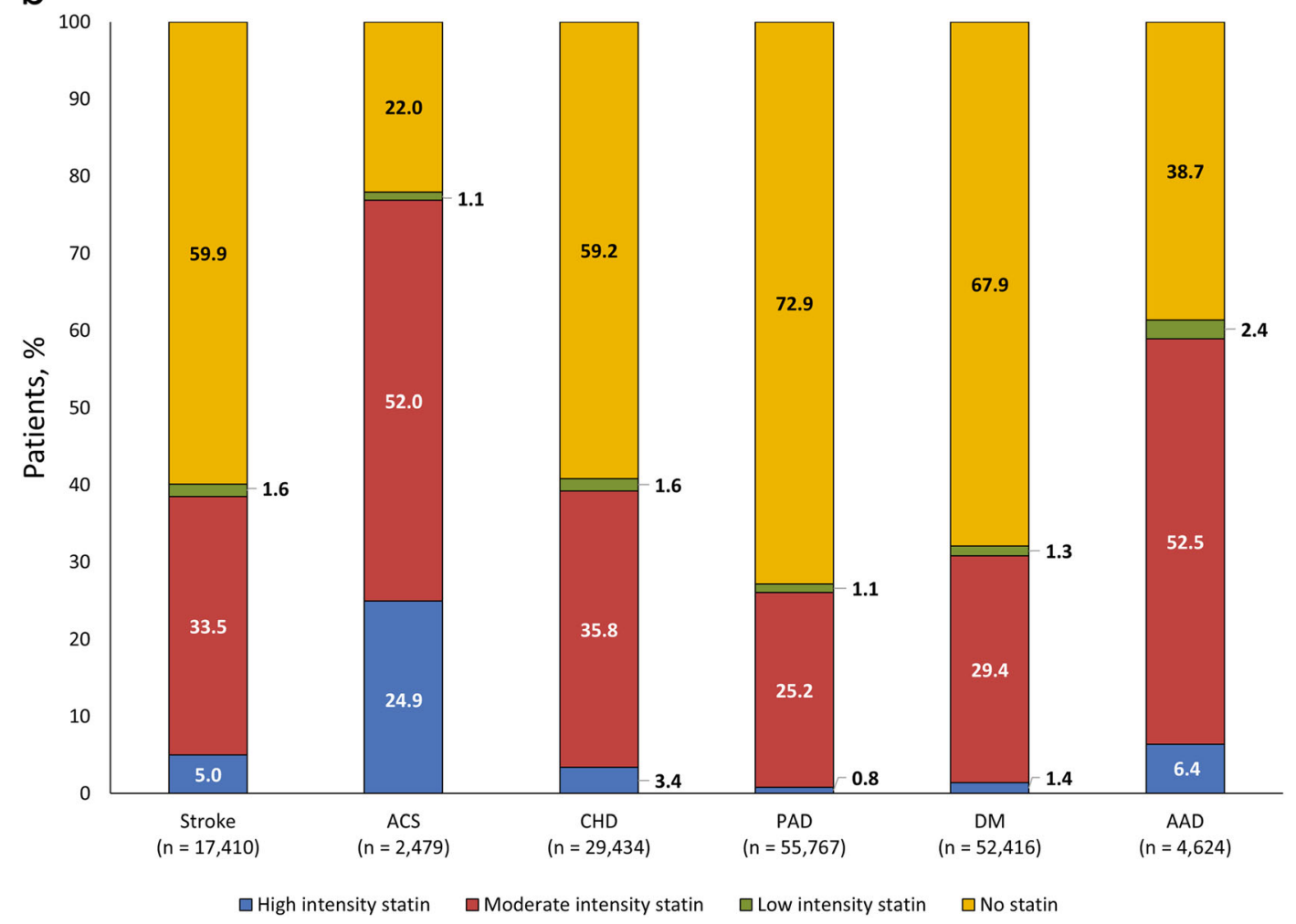

Fig. 2 Statin use in cardiovascular high-risk groups: a. in known high-risk patients and $\mathbf{b}$. in newly defined high-risk patients. AAD, atherosclerotic artery disease; ACS, acute coronary syndrome; CHD, coronary heart disease; DM, diabetes mellitus; PAD, peripheral artery disease 


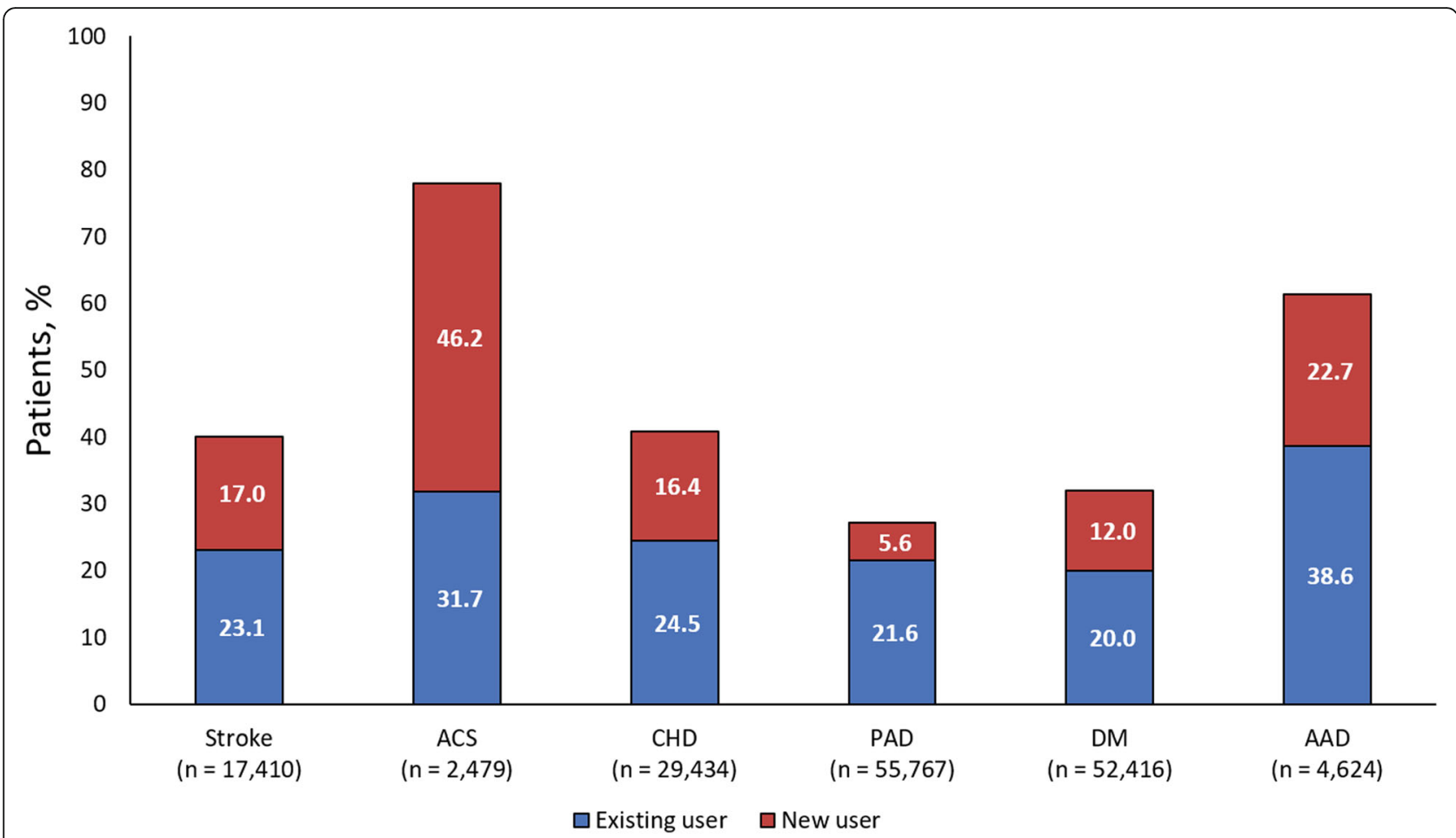

Fig. 3 Patients previously receiving statins (existing user) or newly prescribed statins (new user)

were generally higher in known high-risk patients (36.3\% in $2009,48.7 \%$ in 2015 ) than in newly defined high-risk patients (33.3\% in 2009, 45.0\% in 2015) (Fig. 5).

\section{Discussion}

This retrospective study using the Korean NHIS-HEALS large number database addressed that dyslipidemia management in patients with high-risk for CVD needs to be improved. Although ACS patients who were newly defined high-risk group was the most controlled among the groups (34.4\%), the control of LDL-C levels is still not good enough considering consequence CVD risks and its disease burden. Based on the key findings from this study, LDL-cholesterol level reduction treatment strategies and "treat to-target" groups need to be clarified.

Statin use was highest in patients with ACS or AAD. Overall, 49.4 and 78.0\% of ACS patients with known and newly defined high-risk received statins, respectively, whereas respective figures for patients with AAD were 44.2 and $61.3 \%$. A recent US study found that, although around $90 \%$ of high-risk patients started treatment with statin monotherapy, treatment initiation with highintensity statins was $\leq 10 \%$ [27]. In present study, most patients received moderate-intensity statin therapy; in general, $<10 \%$ of patients received high-intensity statin therapy. The exception was ACS patients with newly defined high-risk, of whom $24.9 \%$ received high-intensity statin therapy.
Guidelines for lipid management in ACS patients vary, and target values, have changed in recent years. 2013 ACC/AHA and 2016 ACC Expert Consensus Guidelines recommend high-intensity statin therapy, which lowers LDL-C levels on average by approximately $\geq 50 \%$, and moderate-intensity statin therapy, which lowers LDL-C on average by approximately 30 to $<50 \%$ for patients aged $>75$ years or who are not candidates for highintensity statin therapy $[3,28]$. These guidelines are also applicable to patients with stroke or other clinical ASCVD events [3, 28]. Current 2018 Korean guidelines recommend LDL-C treatment goals dependent on risk assessment: very high-risk $<70 \mathrm{mg} / \mathrm{dL}$, high-risk $<100$ $\mathrm{mg} / \mathrm{dL}$, moderate-risk $<130 \mathrm{mg} / \mathrm{dL}$, and low-risk $<160$ $\mathrm{mg} / \mathrm{dL}$ [23]. Using 2013 ACC/AHA guideline target values [3], goal attainment rates were relatively high compared to those using the 2018 Korean guidelines, even in the newly defined high-risk patient group (data not shown). For example, in ACS, LDL-C goal attainment rate was $26.3 \%$ by target LDL-C level and $57.8 \%$ by reduction rate. One possible explanation is that doctors treating high-risk patients consider that LDL-C $100 \mathrm{mg}$ / $\mathrm{dL}$ is a sufficiently low attainment level for dyslipidemia treatment, although data derived from KNHANES (2014-2016) show that $17.6 \%$ of adult Koreans (aged $\geq 30$ years) had hyper-LDL cholesterolemia (LDL-C $\geq$ $160 \mathrm{mg} / \mathrm{dL}$ ) [8]. On the other hand, the higher attainment rate by reduction rate than by target LDL-C level, 


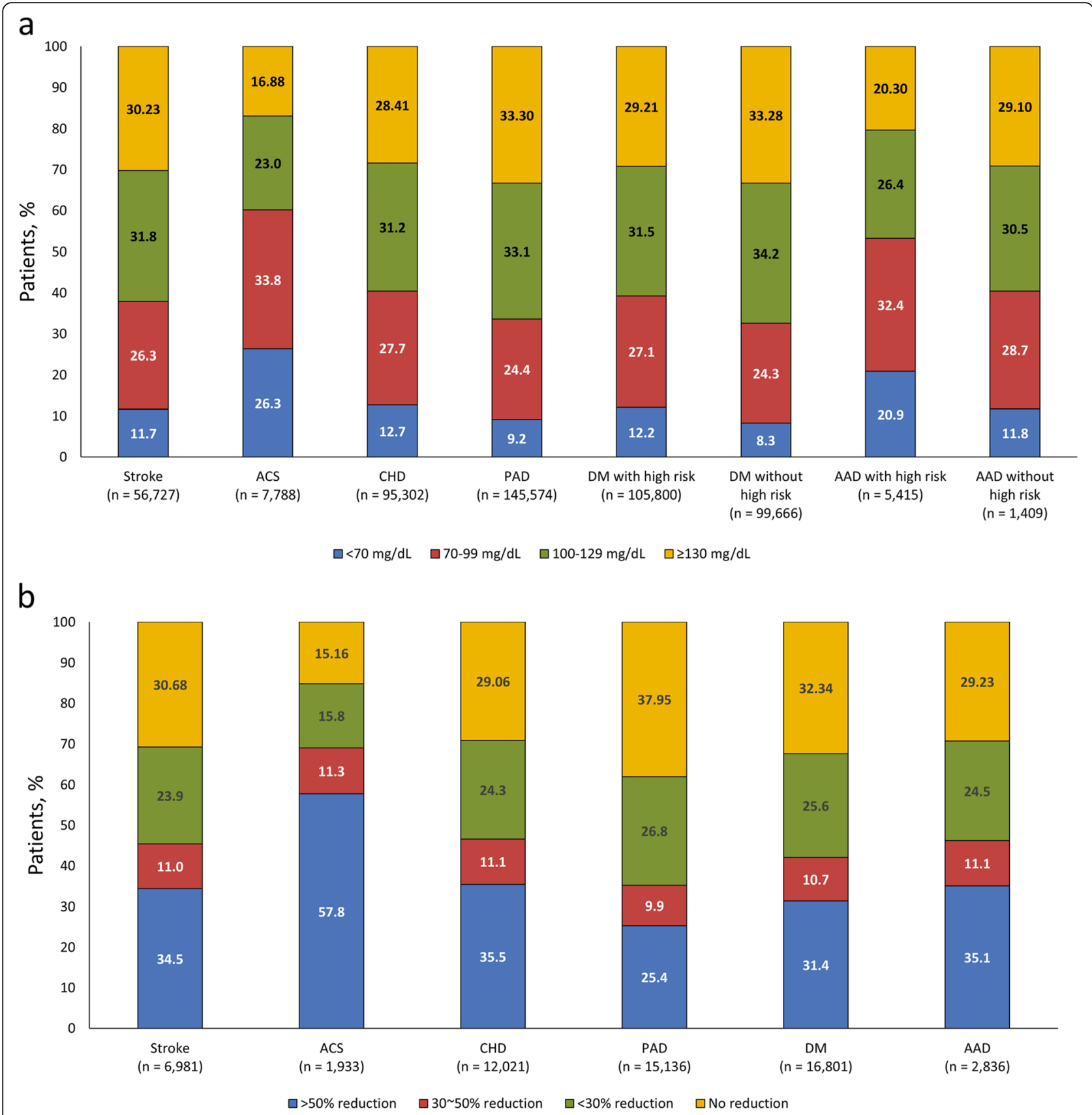

Fig. 4 LDL-C goal attainment rates in a. all high-risk (known + newly defined high-risk patients) by target LDL-C level and b. in newly defined high-risk patients stratified by disease by reduction rate

even though most high-risk patients received moderate intensity statin, may be related to higher statin efficacy in Asians compared to Caucasians [29-32]. Further studies are warranted for more appropriate secondary prevention in high-risk patients.

Time-trend (2009-2015) for LDL-C goal attainment were similar for comparisons of known and newly defined high-risk patients with stroke, CHD, PAD, AAD with additional high-risk disease or DM with/without additional high-risk disease. In ACS, newly defined high-risk patients had consistently higher attainment rates from 2009 to 2015 compared to known high-risk patients. Although reasons for differences were not assessed in this study, they possibly reflect patient medication adherence issues [33, 34], and/or suboptimal performance and poor perception of physicians regarding attainment rates [35], resulting in patients receiving inadequate dosages or titration of lipid-lowering medication [36, 37]. On the other hand, 


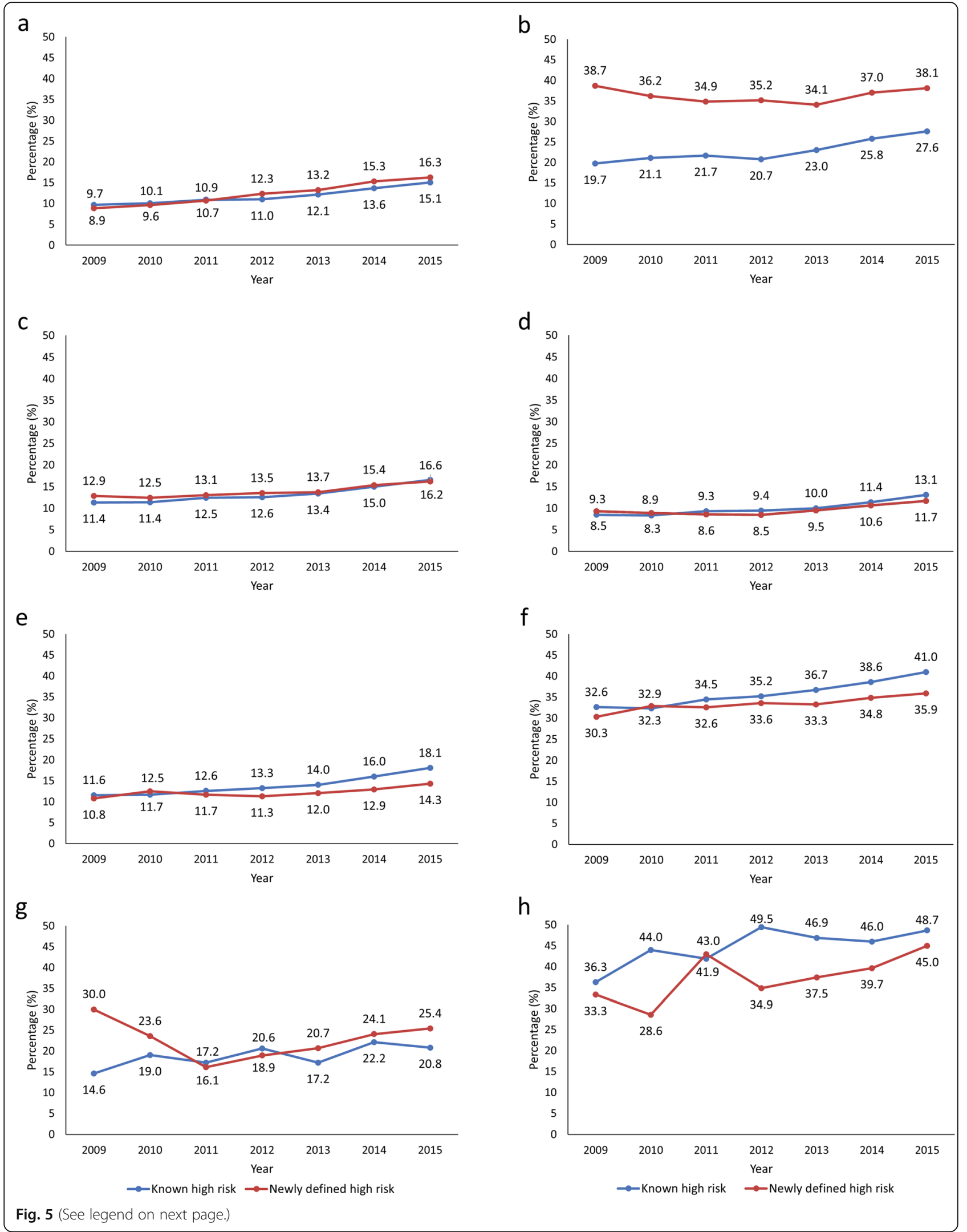


(See figure on previous page.)

Fig. 5 Time trends of goal attainment in known and newly defined high-risk patients with a. stroke; b. ACS; c. CHD; d. PAD; e. DM with high risk of cardiovascular disease (CVD); f. DM without high risk of CVD; $\mathbf{g}$. AAD with high risk of CVD; h. AAD without high risk of CVD. $P$ for trend of known high-risk and newly defined high-risk, respectively. a. $<.0001$ and $<.0001 ;$ b. $<.0001$ and $0.1081 ;$ c. $<.0001$ and $<.0001 ;$ d. $<.0001$ and $<.0001 ;$ e. $<.0001$ and $<.0001 ;$ f. $<.0001$ and $<.0001 ;$ g. 0.0027 and $<.0001 ;$ h. 0.0226 and 0.0138

even though the achievement rate was relatively high in newly defined ACS patients, the gap had been narrowing due to no improvement in newly defined ACS patient. It also reflects suboptimal perception of physicians [35] in newly diagnosed cases, but, further consideration is needed for causes of no improvement of goal attainment in newly defined ACS patients, in contrast to the increase in known ACS patients.

There have been clinical practice changes due to changes in the guidelines such as ACC/AHA [3] and ESC/EAS [15] since the NCEP-ATP III guideline [2]. It was expected that the use of high-intensity statins and the achievement of LDL-C targets in the groups of the high-risk and very high-risk increased. Although the time trends of LDL-C goal attainment had been generally increasing in all groups except newly defined ACS patients, most patients did not achieve LDL-C targets. Attainment rates were $<50 \%$ for patients in each disease category, including the best LDL-C target attainment shown in ACS patients. Even in a previous Korean study of diabetic patients treated by specialists, the LDL-C goal attainment in patients receiving lipid-lowering therapy was low at $47.4 \%$ in 2010 [35]. Comparable results (for 2010) in this study showed LDL-C goal attainment rates of approximately 12 and 32\%, in DM patients with or without additional high-risk disease, respectively. Low rates of LDL-C goal attainment have also been described consistently in other countries, including $58 \%$ of recent ACS patients in the Netherlands [38], 28.8\% of ACS survivors in Hong Kong and Taiwan [39], 30\% of German atherosclerotic CVD patients [40], 41\% of patients with $\mathrm{DM}$ at very-high cardiovascular risk receiving statins in France [41] and 38\% of DM patients with ischemic heart disease in a tertiary hospital in China [42]. In contrast, a higher attainment rate (68\%) for Japan Atherosclerosis Society guideline-recommended LDL-C targets [43] was reported in high-risk patients for CVD in Japan [44].

This study has several strengths. The current study is derived from a nationally-representative cohort of Korean individuals (NHIS-HEALS database, $n=514,866$ ) with a relatively low attrition rate [24], reflecting realworld clinical circumstances. Because information on drug use and bio-clinical laboratory results were included in databases, the risk of recall bias was eliminated. Considering the lack of data in Asian populations for estimating LDL-C goal achievement, results of this study provide information on possible LDL-C reduction rates. In addition, the estimation of goal attainment rate by LDL-C level $(<70 \mathrm{mg} / \mathrm{dL}, 70-100 \mathrm{mg} / \mathrm{dL}$ for target goal) and by percent of LDL-C reduction, together in a large national cohort, is valuable.

However, this study also has some limitations. The result needed to be interpreted with consideration of followings; Subjects were selected based on the availability of LDL-C measurements, which may limit the generalizability of results to general population. Additionally, the age of participant limited between 40 and 70 years and it may not be applicable to goal attainment of young adult participants, or oldest-old participants. In addition, due to the nature of the NHIS-HEALS database, disease diagnosis variables may reflect healthcare usage which is sensitive to the fee-forservice payment and reimbursement system in Korea, rather than being an accurate reflection of a patient's specific medical condition.

\section{Conclusions}

LDL-C goal attainment rates in Korean patients with CVD or with a high-risk for CVD are still poor, with < $50 \%$ of patients achieving LDL-C targets. Proactive action is needed to improve dyslipidemia management in high-risk patients with CVD, including those with stroke or ACS.

\section{Abbreviations}

AAD: Atherosclerotic artery disease; ACC: American College of Cardiology; ACS: Acute coronary syndrome; AHA: American Heart Association; ASCVD: Atherosclerotic cardiovascular disease; BMI: Body mass index; CHD: Coronary heart disease; CVD: Cardiovascular disease; DM: Diabetes mellitus; EAS: European Atherosclerosis Society; ESC: European Society of Cardiology; HDL-C: High-density lipoprotein cholesterol; ICD: International Classification of Disease; IRB: Institutional review board; KNHANES: Korean National Health and Nutrition Examination Survey; LDL-C: Low-density lipoprotein cholesterol; NCEP-ATP: National Cholesterol Education ProgramAdult Treatment Panel; NHIS-HEALS: National Health Insurance ServiceNational Health Screening Cohort; PAD: Peripheral artery disease; SD: Standard deviation

\section{Acknowledgments}

Initial draft preparation and editorial assistance, under the guidance and corrections of the authors, was provided by Robert A. Furlong PhD and David P. Figgitt PhD, ISMPP CMPP'M, Content Ed Net, with funding from Amgen Inc.

\section{Authors' contributions}

All of the listed authors satisfied the following ICMJE guidelines: (1) conception and design of the study, or acquisition of data, or analysis and interpretation of data, (2) drafting the article or revising it critically for important intellectual content, (3) final approval of the version to be submitted, and (4) agreement to be accountable for all aspects of the work in ensuring that questions related to the accuracy or integrity of any part of the work are appropriately investigated and resolved. All authors read and approved the final manuscript. 


\section{Funding}

This study was supported by a research grant from Amgen, Inc.

\section{Availability of data and materials}

The National Health Insurance Service-National Health Screening Cohort (NHIS-HEALS) was third party data owned by the National Health Insurance Corporation (NHIC). Interested researchers can contact NHIC to access the data in the following ways: Tel: 82-33-736-2469 (Big data operation room, NHIC), Web: https://nhiss.nhis.or.kr/bd/ab/bdaba006cv.do

\section{Ethics approval and consent to participate}

This study used an existing database, which was anonymized, with subjects details untraceable during analysis. Consequently, no informed consent or data monitoring process was required for this study. This study was reviewed by the institutional review board (IRB) at Seoul National University Bundang Hospital, and IRB-approved as exempt (IRB number: X-1801-447-903).

\section{Consent for publication}

No informed consent or data monitoring process was required for this study.

\section{Competing interests}

Ye Seul Yang, Bo Ram Yang and Mi-Sook Kim have no conflicts of interest directly relevant to the content of this article. Sung Hee Choi received research funding from Amgen (Amgen study number: 20170708) and Yunji Hwang is employed by Amgen.

\section{Author details}

'Department of Internal Medicine, Seoul National University College of Medicine, 101 Daehak-ro, Jongno-gu, Seoul, Republic of Korea. ${ }^{2}$ Medical Research Collaborating Center, Seoul National University Hospital, 101 Daehak-ro, Jongno-gu, Seoul, Republic of Korea. ${ }^{3}$ Department of Preventive Medicine, Seoul National University College of Medicine, 101 Daehak-ro, Jongno-gu, Seoul, Republic of Korea. ${ }^{4}$ Amgen Korea, 19 Eulji-ro 5-gil, Jung-gu, Seoul, Republic of Korea. ${ }^{5}$ Department of Internal Medicine, Division of Endocrinology \& Metabolism, Seoul National University Bundang Hospital, 82, Gumi-ro 173Beon-gil, Bundang-gu, Seongnam-si, Gyeonggi-do, Republic of Korea.

\section{Received: 17 September 2019 Accepted: 29 November 2019} Published online: 11 January 2020

\section{References}

1. World Health Organization. Cardiovascular diseases (CVDs). http://www.who. int/news-room/fact-sheets/detail/cardiovascular-diseases-(cvds) 2017 (accessed 15 Nov 2018).

2. Expert Panel on Detection, Evaluation, and Treatment of High Blood Cholesterol in Adults. Executive summary of the Third Report of the National Cholesterol Education Program (NCEP) Expert Panel on Detection, Evaluation, and Treatment of High Blood Cholesterol in Adults (Adult Treatment Panel III). JAMA. 2001;285:2486-97. https://doi.org/10.1001/jama.285.19.2486.

3. Stone NJ, Robinson JG, Lichtenstein AH, Bairey Merz CN, Blum CB, Eckel RH, et al 2013 ACC/AHA guideline on the treatment of blood cholesterol to reduce atherosclerotic cardiovascular risk in adults: a report of the American College of Cardiology/American Heart Association task force on practice guidelines. J am Coll Cardiol. 2014;63(25 Pt B):2889-934.

4. Jellinger PS, Handelsman Y, Rosenblit PD, Bloomgarden ZT, Fonseca VA, Garber AJ, et al. American Association of Clinical Endocrinologists and American College of endocrinology guidelines for management of dyslipidemia and prevention of cardiovascular disease. Endocr Pract. 2017;23(Suppl 2):1-87.

5. Kopin L, Lowenstein C. Dyslipidemia. Ann Intern Med. 2017;167:ITC81-96.

6. GBD 2015 Mortality and Causes of Death Collaborators. Global, regional, and national life expectancy, all-cause mortality, and cause-specific mortality for 249 causes of death, 1980-2015: a systematic analysis for the Global Burden of Disease Study 2015. Lancet. 2016;388(10053):1459-544. https://doi.org/10. 1016/S0140-6736(16)31012-1.

7. Joseph P, Leong D, McKee M, Anand SS, Schwalm JD, Teo K, et al. Reducing the global burden of cardiovascular disease, part 1: the epidemiology and risk factors. Circ Res. 2017;121(6):677-94.

8. Korean Society of Lipid and Atherosclerosis. Dyslipidemia Fact Sheets in Korea 2018. http://www.lipid.or.kr/bbs/?code=fact_sheet.
9. Roh E, Ko SH, Kwon HS, Kim NH, Kim JH, Kim CS, et al. Prevalence and Management of Dyslipidemia in Korea: Korea National Health and nutrition examination survey during 1998 to 2010. Diabetes Metab J. 2013:37(6):433-49.

10. Lee YH, Lee SG, Lee MH, Kim JH, Lee BW, Kang ES, et al. Serum cholesterol concentration and prevalence, awareness, treatment, and control of high low-density lipoprotein cholesterol in the Korea National Health and nutrition examination surveys 2008-2010: beyond the tip of the iceberg. J Am Heart Assoc. 2014;3(1):e000650.

11. Jeong JS, Kwon HS. Prevalence and clinical characteristics of dyslipidemia in Koreans. Endocrinol Metab (Seoul). 2017;32(1):30-5.

12. Lee J, Son $\mathrm{H}, \mathrm{Ryu} \mathrm{OH}$. Management status of cardiovascular disease risk factors for dyslipidemia among Korean adults. Yonsei Med J. 2017:58(2):326-38.

13. Committee for the Korean Guidelines for the Management of Dyslipidemia. 2015 Korean Guidelines for the Management of Dyslipidemia: Executive Summary (English Translation). Korean Circ J. 2016;46:275-305. https://doi. org/10.4070/kcj.2016.46.3.275

14. Anderson TJ, Grégoire J, Pearson GJ, Barry AR, Couture P, Dawes M, et al. 2016 Canadian cardiovascular society guidelines for the management of dyslipidemia for the prevention of cardiovascular disease in the adult. Can J Cardiol. 2016;32(11):1263-82

15. Catapano AL, Graham I, De Backer G, Wiklund O, Chapman MJ, Drexel H, et al. 2016 ESC/EAS guidelines for the management of dyslipidaemias. Eur Heart J. 2016;37(39):2999-3058.

16. Choi Y, Lee S, Kim JY, Lee KE. Current guidelines on the management of dyslipidemia. Korean J Clin Pharm. 2017:27(4):276-83.

17. Waters DD, Boekholdt SM. An evidence-based guide to cholesterol-lowering guidelines. Can J Cardiol. 2017;33(3):343-9.

18. Sacks FM, Pfeffer MA, Moye LA, Rouleau JL, Rutherford JD, Cole TG, et al. The effect of pravastatin on coronary events after myocardial infarction in patients with average cholesterol levels. Cholesterol and recurrent events trial investigators. N Engl J Med. 1996;335(14):1001-9.

19. Long-Term Intervention with Pravastatin in Ischaemic Disease Study Group. Prevention of cardiovascular events and death with pravastatin in patients with coronary heart disease and a broad range of initial cholesterol levels. N Engl J Med. 1998;339(19):1349-57.

20. LaRosa JC, Grundy SM, Waters DD, Shear C, Barter P, Fruchart JC, et al. Intensive lipid lowering with atorvastatin in patients with stable coronary disease. N Engl J Med. 2005;352:1425-35.

21. Cholesterol Treatment Trialists' (CTT) Collaboration, Baigent C, Blackwell L, Emberson J, Holland LE, Reith C, Bhala N, et al. Efficacy and safety of more intensive lowering of LDL cholesterol: a meta-analysis of data from 170,000 participants in 26 randomised trials. Lancet. 2010;376:1670-81.

22. Grundy SM, Stone NJ, Bailey AL, Beam C, Birtcher KK, Blumenthal RS, et al. 2018 AHA/ACC/AACVPR/AAPA/ABC/ACPM/ADA/AGS/APhA/ASPC/NLA/ PCNA Guideline on the Management of Blood Cholesterol: Executive Summary: A Report of the American College of Cardiology/American Heart Association Task Force on Clinical Practice Guidelines. J Am Coll Cardiol. 2018 Nov 3. pii: S0735-1097(18)39033-39038. doi: https://doi.org/10.1016/j. jacc.2018.11.002. [Epub ahead of print].

23. Committee of Clinical Practice Guideline of the Korean Society of Lipid and Atherosclerosis. 2018 Korean Guidelines for the Management of Dyslipidemia $4^{\text {th }}$ edition (English version). Available from: http://www.lipid. or.kr/bbs/index.html?code $=$ care \&category $=\&$ gubun $=\&$ page $=1 \&$ number $=903$ $\&$ mode $=$ view\&keyfield $=\& k e y=0$.

24. Seong SC, Kim YY, Park SK, Khang YH, Kim HC, Park JH, et al. Cohort profile: the National Health Insurance Service-National Health Screening Cohort (NHIS-HEALS) in Korea. BMJ Open. 2017;7(9):e016640.

25. Seong SC, Kim YY, Khang YH, Park JH, Kang HJ, Lee H, et al. Data resource profile: the National Health Information Database of the National Health Insurance Service in South Korea. Int J Epidemiol. 2017;46(3):799-800.

26. ICD-10 Version: 2016. http://apps.who.int/classifications/icd10/browse/2016/ en, 2016 ().

27. Punekar RS, Fox KM, Paoli CJ, Richhariya A, Cziraky MJ, Gandra SR, et al. Lipid-lowering treatment modifications among patients with hyperlipidemia and a prior cardiovascular event: a US retrospective cohort study. Curr Med Res Opin. 2017;33(5):869-76.

28. Lloyd-Jones DM, Morris PB, Ballantyne CM, Birtcher KK, Daly DD Jr, DePalma SM, et al. 2016 ACC expert consensus decision pathway on the role of nonstatin therapies for LDL-cholesterol lowering in the Management of Atherosclerotic Cardiovascular Disease Risk: a report of the American 
College of Cardiology Task Force on clinical expert consensus documents. J Am Coll Cardiol. 2016;68(1):92-125.

29. Naito R, Miyauchi K, Daida H. Racial differences in the cholesterol-lowering effect of statin. J Atheroscler Thromb. 2017:24(1):19-25.

30. Lee E, Ryan S, Birmingham B, Zalikowski J, March R, Ambrose H, et al. Rosuvastatin pharmacokinetics and pharmacogenetics in white and Asian subjects residing in the same environment. Clin Pharmacol Ther. 2005;78(4): 330-41.

31. Liao JK. Safety and efficacy of statins in Asians. Am J Cardiol. 2007:99(3):410-4.

32. Kim SK. Re-evaluation of efficacy of moderate-intensity statins in Korean patients with type 2 diabetes mellitus. Diab Metab J. 2017;41(1):20-2.

33. Wouters H, Van Dijk L, Geers HC, Winters NA, Van Geffen EC, Stiggelbout AM, et al. Understanding statin non-adherence: knowing which perceptions and experiences matter to different patients. PLoS One. 2016;11(1): e0146272.

34. Fung V, Graetz I, Reed M, Jaffe MG. Patient-reported adherence to statin therapy, barriers to adherence, and perceptions of cardiovascular risk. PLoS One. 2018;13(2):e0191817.

35. Hwang JY, Jung CH, Lee WJ, Park CY, Kim SR, Yoon KH, et al. Low density lipoprotein cholesterol target goal attainment rate and physician perceptions about target goal achievement in Korean patients with diabetes. Diab Metab J. 2011;35(6):628-36.

36. Diamantopoulos EJ, Athyros VG, Yfanti GK, Migdalis EN, Elisaf M, Vardas PE, et al. The control of dyslipidemia in outpatient clinics in Greece (OLYMPIC) study. Angiol. 2005;56(6):731-41.

37. Hobbs FD, Southworth H. Achievement of English National Service Framework lipid-lowering goals: pooled data from recent comparative treatment trials of statins at starting doses. Int J Clin Pract. 2005;59(10):1171-7.

38. Kuiper JG, Sanchez RJ, Houben E, Heintjes EM, Penning-van Beest FJA, Khan I, et al. Use of lipid-modifying therapy and LDL-C goal attainment in a highcardiovascular-risk population in the Netherlands. Clin Ther. 2017;39(4):81927 e1.

39. Yan BP, Chiang FT, Ambegaonkar B, Brudi P, Horack M, Lautsch D, et al. Low-density lipoprotein cholesterol target achievement in patients surviving an acute coronary syndrome in Hong Kong and Taiwan - findings from the dyslipidemia international study II. Int J Cardiol. 2018;265:1-5.

40. März W, Dippel FW, Theobald K, Gorcyca K, lorga SR, Ansell D. Utilization of lipid-modifying therapy and low-density lipoprotein cholesterol goal attainment in patients at high and very-high cardiovascular risk: real-world evidence from Germany. Atheroscler. 2018;268:99-107.

41. Breuker C, Clement F, Mura T, Macioce V, Castet-Nicolas A, Audurier Y, et al. Non-achievement of LDL-cholesterol targets in patients with diabetes at very-high cardiovascular risk receiving statin treatment: incidence and risk factors. Int J Cardiol. 2018:268:195-9.

42. Hou Q, Yu C, Li S, Li Y, Zhang R, Zheng T, et al. Characteristics of lipid profiles and lipid control in patients with diabetes in a tertiary hospital in Southwest China: an observational study based on electronic medical records. Lipids Health Dis. 2019;18(1):13.

43. Teramoto T, Sasaki J, Ishibashi S, Birou S, Daida H, Dohi S, et al. Executive summary of the Japan atherosclerosis society (JAS) guidelines for the diagnosis and prevention of atherosclerotic cardiovascular diseases in Japan 2012 version. J Atheroscler Thromb. 2013;20(6):517-23.

44. Teramoto T, Uno K, Miyoshi I, Khan I, Gorcyca K, Sanchez RJ, et al. Lowdensity lipoprotein cholesterol levels and lipid-modifying therapy prescription patterns in the real world: an analysis of more than 33,000 high cardiovascular risk patients in Japan. Atheroscler. 2016;251:248-54

\section{Publisher's Note}

Springer Nature remains neutral with regard to jurisdictional claims in published maps and institutional affiliations.

Ready to submit your research? Choose BMC and benefit from:

- fast, convenient online submission

- thorough peer review by experienced researchers in your field

- rapid publication on acceptance

- support for research data, including large and complex data types

- gold Open Access which fosters wider collaboration and increased citations

- maximum visibility for your research: over $100 \mathrm{M}$ website views per year

At BMC, research is always in progress.

Learn more biomedcentral.com/submissions 